\section{United airways disease among florists}

\author{
Muge Akpinar-Elci, ${ }^{1}$ Omur Cinar Elci, ${ }^{1}$ \\ Aygul Odabasi
}

1Department of Public Health and

Preventive Medicine, School of Medicine,

St. George's University, Grenada, WI;

2Department of Respiratory Medicine,

Izan Hospital, Milas, Turkey

\begin{abstract}
Previously we observed an excess risk for occupational asthma among florists with rhinitis. To further evaluate the link between upper and lower airways, we investigated united airways disease in the same occupational group. Occupational history, symptoms and atopy were investigated among 128 florists. Age-, smoking-, and gender-adjusted risks were calculated using logistic regression models comparing symptomatic and asymptomatic individuals. The prevalence of work-related rhinitis symptoms was $13.3 \%$, conjunctivitis symptoms and asthma-like symptoms were $14.1 \%$. We observed an excess risk of work-related asthma symptoms among florists with work-related conjunctivitis (OR: 8.5, 95\% CI: 2.4-29.9) and rhinitis (OR: 13.1, 95\% CI: 3.0- 58.0). Florists with positive allergen skin test for flower mix were 13.0 times more likely to have work-related rhinitis and 12.5 times more likely to have work-related conjunctivitis. The observed relationship between work-related asthma and rhinoconjunctivitis is supportive of the concept of the united airways disease.
\end{abstract}

\section{Introduction}

The nasal passages are the first contact point for a respiratory exposure, so rhinitis is both as an indicator of exposures and a precursor to more severe respiratory conditions. The inflammatory responses elicited in the upper and lower airways are pathophysiologically similar and related.. ${ }^{1}$ Allergic rhinitis is now regarded as a risk factor for asthma and it has been shown that rhinitis frequently precedes asthma. ${ }^{2-5}$ The frequency of the co-existence between rhinitis and asthma has led to the concept of the united airways disease ${ }^{6}$ and the World Health Organization is leading an initiative to develop a treatment for both conditions simultaneously. ${ }^{7}$ Many studies have demonstrated that lower airway conditions are less severe after treating upper airway conditions ${ }^{5,8,9}$ or that lower airway diseases may be prevented by treating rhinitis. ${ }^{10}$ This indicates that early detection and appropriate management of upper airways diseases may be an important component in preventing other conditions, such as asthma or allergic diseases.

Our previous investigations demonstrated a strong relationship between occupational asthma and work-related factors such as work intensity, work duration, and other factors including specific atopy among florists. ${ }^{11}$ To further investigate the link between upper and lower airways, we planned to expand this investigation by focusing on occupational risk factors, rhinoconjunctivitis and their relationship with asthma like symptoms among florists. In the floral industry, there are various potential allergens; case reports of occupational allergic dermatitis have been published frequently. There are only a few case reports on occupational rhinoconjunctivitis caused by flowers. ${ }^{12,13}$ The novelty of this study is being the first to focus directly on the upper airways health problems and its relationship with the lower airways health problems to evaluate united airways disease among florists.

\section{Materials and Methods}

The overall investigation focused on the multiple components of occupational respiratory health problems among florists. Methodological study details of the project can be found in the previous publication from this project.

\section{Study population}

This study was conducted in Izmir, the third largest city in Turkey, which is located on the western shore. A list of registered floral shops was provided from the city municipality records; and because of the small number, to our study, we invited all registered floral shops $(n=69)$ to participate in the study. Nine shops were excluded because three were closed at two different scheduled visits and six others refused to participate. Data were collected from 60 floral shops with a total of 159 workers, of whom $128(80.5 \%)$ agreed to participate in the study. Data was collected by two experienced pulmonologists to provide accuracy. The Institutional Review Board of the Izmir Chest Diseases Hospital approved the study procedures and all participants provided informed consent.

\section{Questionnaire}

Demographic data, allergic and respiratory symptoms, family and personal history of respiratory and allergic diseases, medication, smoking and occupational history, were collected by using a modified American Thoracic
Correspondence: Muge Akpinar-Elci, Department of Public Health and Preventive Medicine, School of Medicine, St. George's University, P.O. Box 7, St. George's, Grenada, West Indies.

Tel. 473.444.4175 ext. 3668 - Fax: 473.444.1219.

E-mail: makpinarelci@sgu.edu

Key words: flower, work-related, conjunctivitis, rhinitis, asthma, atopy, epidemiology.

Contributions: OCE, A0, data interpretation, article drafting and conception; MAE, study design; OCE, data analysis; $\mathrm{AO}$, data management and collection.

Conflict of interest: the authors report no conflicts of interest.

Received for publication: 27 July 2011.

Accepted for publication: 7 September 2011.

This work is licensed under a Creative Commons Attribution NonCommercial 3.0 License (CC BYNC 3.0).

(OCopyright M. Akpinar-Elci et al., 2011

Licensee PAGEPress, Italy

Chest Disease Reports 2011; 1:e10

doi:10.4081/cdr.2011.e10

Society (ATS) questionnaire work-site personal interviews.

Florists were asked if they had any one of the following recurrent symptoms for rhinitis: blocked nose, sneezing, itching of the nose, or rhinorrhea. Participants were also asked if they had any one of the following recurrent symptoms for conjunctivitis: itching of eyes, redness, or watery eyes and for asthma; nonproductive cough, dyspnea; chest tightness; or wheezing. By asking standard questions, we collected the following information: did these symptoms begin and exist within the overall working period as a florist, and did symptoms improve when the person was away from work.

\section{Work area evaluation}

At each florist shop, area $\left(\mathrm{m}^{2}\right)$, humidity (\%), and temperature $\left(\mathrm{C}^{\circ}\right)$ (Met-Check, Milton Keynes, United Kingdom) were measured near the end of the work shift on the day of our visit. Participant florists were asked whether they had effective local exhaust ventilation systems operational during working hours in their shops. Based on the distribution of area measurements, shops with an area $100 \mathrm{~m}^{2}$ or above were categorized as large shops and compared with medium size (51-99 $\mathrm{m}^{2}$ ) and small shops ( $50 \mathrm{~m}^{2}$ or below). Work intensity was calculated from the daily work hours multiplied by the work duration (hours $\mathrm{x}$ years). Florists were categorized in low (less than 35), medium (35$167)$, or high (168 and higher) work intensity groups. 


\section{Skin prick test}

Atopy for the most common allergens in the region (D. farinae, D. pteronyssinus, Mold mix $)^{14}$ and for the commonly used flower mix (Aster chinensis, Chrysanthemum koreanum, Dahlia cultorum, Solidago virgaurea, Chrysanthemum leucanthemum) were evaluated by skin-prick test (Stallergenes-Pasteur, Antony, France). Fifteen minutes after application, wheal of five millimeters or larger than the control was considered as atopy positive.

\section{Statistical analysis}

Using the SPSS statistical software package version 11.01, we evaluated occupational risk factors by age-, smoking- (pack-years), and gender-adjusted unconditional logistic regression models comparing symptomatic and asymptomatic florists.

\section{Results}

The median age of florists was 28.0 years (12-66 years), $85.9 \%$ were male while $63.3 \%$ reported as a smoker. Seventeen florists (13.3\%) reported symptoms consistent with work-related rhinitis and 18 florists (14.1\%) reported symptoms consistent with work-related conjunctivitis. The prevalence of work-related asthma-like symptoms was $14.1 \%(n=18)$.

In age-, smoking- and gender-adjusted analyses, we observed an excess risk of workrelated asthma symptoms among florists with work-related conjunctivitis (OR: $8.5,95 \% \mathrm{CI}$ : 2.4-29.9) and rhinitis (OR: 13.1, 95\% CI: 3.058.0) (Table 1). Risk for work-related conjunctivitis was 12.3 times higher among florists in the high-work intensity group when compared with the low-work intensity group. There was a statistically significant dose-response relationship between work intensity and work-related conjunctivitis $(\mathrm{P}<0.05)$ and non-significant dose-response relationship between work intensity and rhinitis. We observed excess risk for work-related conjunctivitis among florists who had been working for more than 10 years. Florists with positive allergen skin test for flower mix were 13.0 times more likely to have work-related rhinitis and 12.5 times more likely to have work-related conjunctivitis and 11.7 (95\% CI: 1.9-73.2) times more likely to have work-related rhinitis and asthma combination.

\section{Discussion}

In this study, rhinitis and conjunctivitis were found to be associated with work-related asthma. It was suggested that the link between upper airway disease and lower airways disease led to the concept of the united airways disease. ${ }^{15}$ Generally, allergic conjunctivitis occurs with other allergic diseases such as allergic rhinitis and allergic asthma. ${ }^{16}$

According to our results, the most apparent risk factor for work-related conjunctivitis was work intensity. Finding a positive dose- response relationship between work intensity and work-related symptoms supported the occupational exposure and accuracy of our questionnaire-based diagnosis. Previous studies noted that the work intensity was one of the objective factors for evaluating occupational exposures. ${ }^{11,17}$ Work duration was also associated with the risk of work-related conjunctivitis. We also observed elevated risk with work intensity and duration in work-related rhinitis. However, they were not excessive, perhaps due to the healthy-worker effect.

Goldberg reported the incidence of positive skin-prick test responses to ornamental plants was $17 \%$ to $23 \%$ among the general population but $52 \%$ among flower growers. ${ }^{18}$ Monso et al. reported a $21 \%$ prevalence of sensitization to cultivated flowers in greenhouse growers. ${ }^{19}$ Allergy for flower mix was an important risk factor among our study participant and this might be evidence of the occupational exposure.

Conditions of the work place including ventilation and humidity also played an important role in occupational exposure among florists. Monso reported that high indoor temperature and humidity facilitate air contamination in greenhouses and that green house worker easily sensitize against moulds and flower pollens..$^{20}$ In our study, high humidity increased the risk of work-related conjunctivitis. Florist working without ventilation also had a 3.1 times high risk of occupational rhinitis $(95 \%$ $\mathrm{CI}=0.8-11.6$ ).

The high participation rate from scarcely

Table 1. Risk of work-related rhinitis and conjunctivitis among florists.

\begin{tabular}{|c|c|c|c|}
\hline \multirow{2}{*}{ Risk factors } & \multirow[b]{2}{*}{$\begin{array}{l}\text { Overall } \\
n=128 \\
(n / \%)\end{array}$} & \multicolumn{2}{|c|}{ OR $(95 \% \mathrm{CI})^{*}$} \\
\hline & & $\begin{array}{l}\text { Work-related rhinitis } \\
\qquad \mathrm{n}=17\end{array}$ & $\begin{array}{l}\text { Work-related conjunctivitis } \\
\qquad \mathrm{n}=18\end{array}$ \\
\hline Work-related Asthma & $18 / 14.1$ & $13.1(3.0-58.0)$ & $8.5(2.4-29.9)$ \\
\hline $\begin{array}{l}\text { Work intensity (hours x years) } \\
\text { Low }(\leq 35) \\
\text { Medium }(36-167) \\
\text { High }(\geq 168)\end{array}$ & $\begin{array}{l}38 / 29.7 \\
47 / 36.7 \\
43 / 33.6\end{array}$ & $\begin{array}{l}1.00 \text { (reference) } \\
2.8(0.5-16.1) \\
3.1(0.5-18.6)\end{array}$ & $\begin{array}{c}1.00 \text { (reference) } \\
8.6(0.9-78.2) \\
12.3(1.2-128.1) \\
\end{array}$ \\
\hline Work duration (years) & & & \\
\hline $\begin{array}{l}<10 \\
\geq 10\end{array}$ & $\begin{array}{l}63 / 49.2 \\
65 / 50.8\end{array}$ & $\begin{array}{l}1.00 \text { (reference) } \\
2.2(0.6-8.2)\end{array}$ & $\begin{array}{l}1.00 \text { (reference) } \\
3.9(1.0-15.9)\end{array}$ \\
\hline $\begin{array}{l}\text { Work area size }\left(\mathrm{m}^{2}\right) \\
\quad \geq 100 \\
51-99 \\
\leq 50 \\
\text { No ventilation }\end{array}$ & $\begin{array}{l}30 / 65.5 \\
14 / 10.9 \\
84 / 23.4 \\
50 / 39.1\end{array}$ & $\begin{array}{l}1.00 \text { (reference) } \\
1.3(0.3-6.7) \\
1.2(0.3-4.8) \\
3.1(0.8-11.6)\end{array}$ & $\begin{array}{l}1.00 \text { (reference) } \\
0.8(0.1-4.5) \\
1.2(0.3-4.4) \\
1.4(0.5-4.2)\end{array}$ \\
\hline Temperature $\left(\geq 19^{\circ} \mathrm{C}\right)$ & $84 / 65.5$ & $1.0(0.3-3.5)$ & $0.1(0.1-0.8)$ \\
\hline Humidity ( $\geq 58 \%$ ) & $64 / 50$ & $0.9(0.3-2.6)$ & $3.2(1.0-10.0)$ \\
\hline $\begin{array}{l}\text { Atopy } \\
\text { General allergen } \\
\text { Flower mix }\end{array}$ & $\begin{array}{l}11 / 8.6 \\
12 / 9.4\end{array}$ & $\begin{array}{c}0.7(0.1-4.6) \\
13.0(3.1-55.3)\end{array}$ & $\begin{array}{c}1.8(0.4-8.3) \\
12.5(3.1-49.9)\end{array}$ \\
\hline Family history on respiratory and/or allergic problems & $31 / 24.2$ & $3.3(1.1-10.3)$ & $2.5(0.8-7.5)$ \\
\hline
\end{tabular}


distributed, small workshops and our standard work-site data collection method are the main strengths of this study. A major limitation is the absence of further diagnostic techniques. However, several previous epidemiologic studies also used questionnaire-based symptoms to define rhinitis. We did not collect samples to measure actual exposure levels, due to observed similar working conditions. However, we do not expect that exposure differences would be a significant factor between workshops. Using semi-quantitative methods for exposure estimation might increase the risk of uncertainty and misclassification. Lack of a control group (unexposed), cross-sectional design, and possible healthy worker effect are other limitations that readers should consider while interpreting our results. However most of the florist shop workers were also the owners of the shop and due to economic reasons healthy worker effect concept may not apply easily in this case.

In conclusion, rhinitis and conjunctivitis were associated with work-related asthma. This relationship might support the concept of the united airways disease. Research into the link between occupational exposures and upper airways health problems is crucial in order to determine which exposures are most likely to cause upper airways and lower airways health problems. This can also inform appropriate preventive measures which can be taken also including the education of florists about the consequences of health problems. Such information has had an impact on the prevention and the management of respiratory disease. This implies that treating less severe upper airways symptoms may also effectively prevent or treat more severe lower airways diseases, such as asthma, which will lead to increased productivity in the workforce.

\section{References}

1. Camargos PA, Rodrigues ME, Sole D, Scheinmann P. Asthma and allergic rhinitis as symptoms of the same disease: a paradigm under construction. J Pediatr (Rio J) 2002;78 Suppl 2:S123-8.

2. Braunstahl GJ, Hellings PW. Nasobronchial interaction mechanisms in allergic airways disease. Curr Opin Otolaryngol Head Neck Surg 2006;14:176-82.

3. Corren J, Kachru R. Relationship between nonallergic upper airway disease and asthma. Clin Allergy Immunol 2007;19:101-14.

4. Gonzalez Diaz SN, Arias Cruz A. Allergic rhinitis and ashtma: 2 illnesses. The same disease? Rev Alerg Mex 2002;49:20-4.

5. Virchow JC. Asthma, allergic rhinitis, sinusitis. Concept of the "unified respiratory tracts". HNO 2005;53 Suppl 1:S16-20.

6. Passalacqua G, Ciprandi G, Canonica GW. The nose-lung interaction in allergic rhinitis and asthma: united airways disease. Curr Opin Allergy Clin Immunol 2001;1:7-13.

7. Pawankar R. Allergic rhinitis and its impact on asthma: an evidence-based treatment strategy for allergic rhinitis. Asian Pac J Allergy Immunol 2002;20:4352.

8. Rimmer J, Ruhno JW. Rhinitis and asthma: united airway disease. Med J Aust 2006;185:565-71.

9. Vinuya RZ. Upper airway disorders and asthma: a syndrome of airway inflammation. Ann Allergy Asthma Immunol 2002; 88:8-15.

10. Ferguson B, Powell-Davis A. The link between upper and lower respiratory disease. Curr Opin Otolaryngol Head Neck Surg 2003;11:192-5.
11. Akpinar-Elci M, Elci OC, Odabasi A. Workrelated asthma-like symptoms among florists. Chest 2004;125:2336-9.

12. Piirila P, Kanerva L, Alanko K, et al. Occupational IgE-mediated asthma, rhinoconjunctivitis, and contact urticaria caused by Easter lily (Lilium longiflorum) and tulip. Allergy 1999;54:273-7.

13. Uter W, Nohle M, Randerath B, et al. Occupational contact urticaria and latephase bronchial asthma caused by compositae pollen in a florist. Am J Contact Dermat 2001;12:182-4.

14. Kalyoncu AF, Coplu L, Selcuk ZT, et al. Survey of the allergic status of patients with bronchial asthma in Turkey: a multicenter study. Allergy 1995;50:451-5.

15. Bousquet J, Vignola AM, Demoly P. Links between rhinitis and asthma. Allergy 2003; 58:691-706.

16. Groneberg DA, Bielory L, Fisher A, et al. Animal models of allergic and inflammatory conjunctivitis. Allergy 2003;58:1101-13.

17. Akpinar-Elci M, Elci OC. Importance of work intensity on respiratory problems in hairdressers. Occup Environ Med 2002;59: 649-50.

18. Goldberg A, Confino-Cohen R, Waisel Y. Allergic responses to pollen of ornamental plants: high incidence in the general atopic population and especially among flower growers. J Allergy Clin Immunol 1998;102:210-4.

19. Monso E, Magarolas R, Badorrey I, et al. Occupational asthma in greenhouse flower and ornamental plant growers. Am J Respir Crit Care Med 2002;165:954-60.

20. Monso E. Occupational asthma in greenhouse workers. Curr Opin Pulm Med 2004; 10:147-50. 